\title{
Impact of Knowledge Management Process on Managerial Performance in the High Tech Sector
}

\author{
Bechir Brahmi $^{1}$ \& Malik Mustafa ${ }^{2}$ \\ ${ }^{1}$ Community College of Qatar, C Ring Rd, Doha, Qatar \\ ${ }^{2}$ School of Economics, Peking University, Beijing, China \\ Correspondence: Malik Mustafa II, School of Management, Faculty Business and Management Studies, Gulf \\ College, Maabela, P. O. Box 885, Muscat, Oman. E-mail: malik@gulfcollege.edu.om
}

Received: December 5, 2018

doi:10.5539/ijbm.v14n2p155

\begin{abstract}
This study used two mixed methods are qualitative and quantitative methods, qualitative methods were analysed using semi structured techniques based on interviews and case studies. Whereas, the quantitative methods were analyzed using the Statistical Package for Social Science. Descriptive analysis based on frequencies and percentages was performed to define the major demographic characteristics of the respondents. This study aimed at identifying the major factors that affect KMP, KOL, KM dynamic capabilities, and innovation performance, in particular, influence of knowledge management on managerial performance services in developing countries. The results of this study are expected contribute to in-depth understanding of how factors affect adoption of in the high tech sector in developing countries and play critical role in improving the level of their using. Keywords: low case, comma, paper template, abstract, keywords, introduction
\end{abstract}

\section{Introduction}

Leaders of successful organizations are consistently searching for better ways to improve performance and results. Frequent disappointments with past management initiatives have motivated managers to gain new understandings into the underlying, but complex mechanisms - such as knowledge - which govern an enterprise's effectiveness. Knowledge Management, far from being a management "fad", is broad, multi dimensional and covers most aspects of the enterprise's activities. To be competitive and successful, experience shows that enterprises must create and sustain a balanced intellectual capital portfolio. They need to set broad priorities and integrate the goals of managing intellectual capital and the corresponding effective knowledge processes. This requires systematic Knowledge Management. With knowledge as the major driving force behind the "economics of ideas", we can expect that the emphasis on knowledge creation, development, organization and leverage will continue to be the prime focus for improving society.

The emergence of a knowledge-based innovation economy (Cohendet, 2005; Foray, 2009) is causing major upheavals in the managerial area by focusing our attention on the issue of the emergence, capitalization and diffusion of knowledge (Nonaka \& Takeuchi, 1995). The term KM affects everything that is knowledge and information within the company through the Intranet, perceived as the greatest technological tool used. Indeed, intranet, seminars and documentary management are the main tools for exchange and collaboration to get positive feedback on the process defined as a process of exchange and collaboration on the one hand, and recovery these various tools, on the other hand. Ultimately: "The goal is the participation and feeding of employees.

Among other components, the affiliation of contemporary organisations on the knowledge production process urges constantly acquire an ideal type of knowledge network(Ebrahimi \& Blum, 2014), not only internally, through what we have mentioned in terms of trade and collection data, but also externally, through acquisitions, partnerships and recruitment of experts in the field of interactivity. These efforts have greatly helped to acquire new knowledge, technical expertise and administrative according to a policy referred to in the annual report of so many contemporary enterprises. However, knowledge management provides very little in terms of organizational culture due to lack of formal channel of integration of the tacit knowledge (Lievre, 2012).

Indeed, such approaches to improving internal knowledge and expertise does not materialize in the form of 
written policies, structured and accessible that reflect this desire and these guidelines. This is because these actions have been accumulated over time in an informal way or they were imposed by the headquarters under market pressure and competition. The informal network is so far the source of most exchanges and sharing between employees. The management of knowledge in companies is representing through tools and technological methods in most cases and it represents a certain competitive advantage. However, the criticism on the shortcomings such as lack of motivation, lack of communication and non-formal adoption of KM in the process of work, which are sources of concern for managers and employees.

\subsection{The Subject Problematic}

The high speed of changes had occurred in the economy, particularly in industrialized societies, and the need to cope with new demands of competition has forced companies to move permanently. Due to the globalization of markets, the growing importance of the knowledge economy and the integration of new technologies, companies must put new challenges, sometimes paradoxical. Thus, companies had to make their structures and production process very flexible. This has enabled them to adjust quickly to market demands and offer products and services appropriate. Nevertheless, as regards the management of knowledge and learning, which in the current context, becomes a very important strategic issue, the changes are slow to be felt on the ground. Indeed, although this issue raises an ideological debate, knowledge in question are difficult to manage in reality as they include the components of tacit and informal axes

On the issue of difficulties inherent in the implementation of knowledge management that brings our problem. For instance, we can introduce the difficulties of Canadian High technology sector to implement the all KM process in all organisation level due to the classic culture which make a real obstacle for the implementation of knowledge management process on the way of managing. To properly define the study problem that relates to The Knowledge management (KM), we chose to treat stating research questions and sub-issues that arise: Can the managerial approaches increase the efficiency of the organization as a learning one?

Does the knowledge management contributes really to make the organization more efficient both in financial and organizational level?

What kind of approaches (technological, organizational or other) at one resort for implementing knowledge management as engine performance and innovation?

How the knowledge they are established, capitalized and disseminated?

Is this the humanist approach or financial approach which allows for the creation of knowledge?! These questions are so present because, as we noted earlier, organizational performance of the current high-tech firm based in large part on intangibles as a source of innovation and value added. This value is the result of a new conception of the organization-oriented learning, and tacit knowledge transfer, provides a competitive advantage. (Nonaka \& Takeuchi, 1997; Melville \& Ali, 2004; Shin, 2004). This research lies at the intersection of studies on new forms of management organizations, knowledge management and innovation, and the new economy. The final question is what's the real impact of knowledge management on the organisational performance?

\subsection{Study Objective}

In conclusion, this research has enabled us, firstly to dissect the various changes of tools, ways of doing and managerial visions concerning the sources of wealth of these organizations, and secondly to analyse the managerial process of wealth creation and its link with the creation of knowledge, perspectives and expectations down and bottom-intra and inter organizational.

\section{Literature Review}

This section included the tacit knowledge, explicit knowledge, the information technology approach, the knowledge management literature review, and conceptual framework, illustrated as following:

\subsection{The Knowledge Management Concept}

The fast evolution of economies has carried the real wealth of companies in the intangible instead of tangible assets. (Edvisson \& Malone, 1997). The important growing of the knowledge economy and integration of new technologies are causing companies to take on new challenges in trying systematically to acquire new knowledge and create new expertise to counter competition and targeting the innovation. Innovation, as a key concept, can only take place with the involvement of human skills at all levels and in all structures of the company (Nonaka \& Takeuchi, 1997).

Accordingly, with the advent of the new economy, the mobilization of knowledge and learning becomes a strategic issue of prime importance especially for companies working in the field of high technology. This is 
because the company of yesterday was an organization that knew produce and sell following a traditional model of production based on mechanical routine, while the company of the new information age does may perform only through continuous innovation. Nevertheless, this innovation can take place only through the mobilization and integration of the collective intelligence of all stakeholders and the establishments of a management style capable of guiding, capitalize, distribute and store information, knowledge and expertise at all levels of the organization (Nonaka \& takeuchi, 1997). In addition, developing a strategy should be based on a growing visibility of the importance of knowledge, on the role assigned to the various actors, as well as confidence on the added value of the approach of KM (Knowledge Management). These aspects are the real challenges that businesses face to satisfy the requirements of competition and high level of performance in the new economic era. Due to the economic relevance of the topic, we chose the field of high technology because it is one of the most representative sectors of the importance of intellectual or intangible capital for innovation and wealth creation in the form of patents, Knowledge, expertise, skills or other trades.

\subsection{Tacit Knowledge}

Polanyi (1967) defines the tacit knowledge as "non-verbalisables knowledge, intuitive and non-articulate." For instance, the fact of having new technological ideas for implementing new process for the cell phone is a result of the tacit knowledge based on intuitive spirit which can't be articulate easily.It demands the observation and the adoption of this creative spirit more than the verbalisable and the articulate way. Nonaka and Takeuchi (1994), as Polanyi $(1962,1966)$ argue that tacit knowledge can be gained and operated by a collaborative experience based on innovative organisation(Hamel,2008), but it remains difficult to articulate, to formalise and communicate (Dudezert \& Boughzala, 2007). As a result, it can not be transmitted directly from a codified way. Aligned on the same design, Leonard and Sensiper (1998) describe the tacit knowledge as being hidden, intangible, subjective and spontaneous. They arise indeed, our own experiences and come straight from our unconscious or our subconscious.

\subsection{The Explicit Knowledge}

About the explicit, Hall and Andriani (2003) had demonstrated that "knowledge has been captured in a code or a language that facilitates communication. "As a result, it" involves the know-how transmissible on a formal and systematic language; it requires direct experience of knowledge». The following explains the interaction between tacit and explicit knowledge creation within an organization, in Figure 1. The knowledge management process.

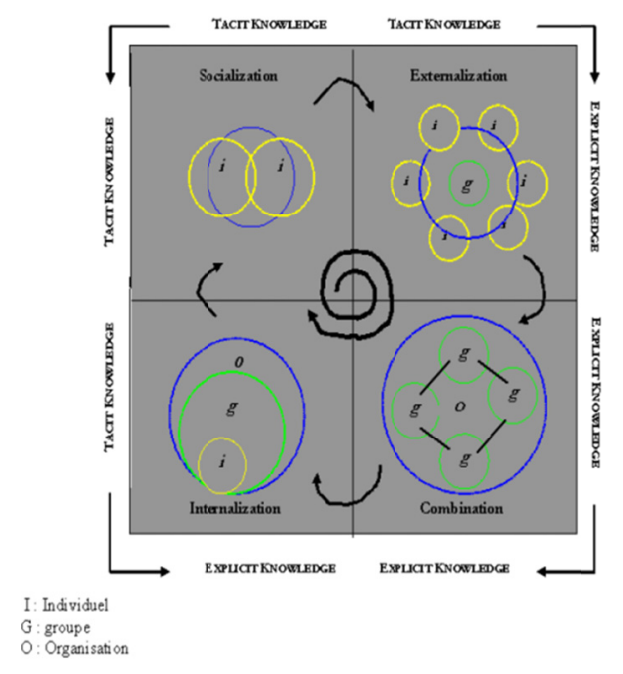

Figure 1. The knowledge management process

Source: (Nonaka, 1995).

Through this scheme, Nonaka and Takeuchi (1997) consider that all ontological levels within the organisation are implemented in the acquisition and dissemination of knowledge. Nonaka and Takeuchi gave the example of chef preparing pizza, only imitation and observation due to empathy, mutual trust, the will to help and courage can explore and act out the talent of this chef, because the knowledge and talent is written nowhere. After externalization of tacit knowledge, we can pass to its collective aspect by diffusing across the organization 
(socialization) in all the departments (internalization). This interactive system of diffusing tacit knowledge can create the positive interaction between tacit and explicit knowledge.

\subsection{The Information Technology Approach}

Zara (2005) adds that the idea of the importance of technological approach. Indeed, information technology and communication are an integral part of this approach. They can create, capture, manipulate, communicate, exchange and use information. (Boughzala \& Ermine, 2007). When we talk about information technology, we think, among others, blog, wiki, and search engine. The communication, it operates through electronic mail, workflow and e-learning

Two other parameters added to the definition of Zara (2005): those of collaboration and management. The collaboration, the third aspect of this approach is illustrated by discussion forums and e-coaching, while the management integrates collaboration tools and processes of individual and collective management. Also according to Zara, collaboration and management also play an important role in human interactions. They allow the effective use of technology as reflected in the explanatory table below. The latter identifies the importance of information transactions in levels one and two (information, communication) and mentions the importance of human interactions in levels three and four (collaboration and management). For example, the diffusion of a tacit knowledge can't be successfully done without real collaboration based on empathy, the will to help and courage to transfer the information for the group. Similarly to this procedure, an interactive management system will help clearly this operation to success by giving the possibility for this actor to communicate on real time by intranet and working in flexible hours to have more motivation to externalize their expertise, knowledge and experiences easily without being under pression of time and production (See Table 1).

Table 1. Informational transactions and human interactions

\begin{tabular}{lll}
\hline & Informational transactions & Human interactions \\
\hline Information & ++++ & + \\
Communication & +++ & ++ \\
Collaboration & ++ & +++ \\
Management & + & ++++ \\
\hline
\end{tabular}

Castells (1996) has enhanced the technological approach for its effects on communication and collaboration between enterprises. He argues that the information and communication technologies (ICT) have profoundly transformed the nature of work. By decentralizing the managerial responsibilities and individual tasks, ICT has allowed more flexibility in time and space.

\subsection{The Consensual Approach}

For Aktouf (1999) and Zara (2005), Dudezert, (2007), the approach is based on the involvement of employees willing to take initiatives and to share decision-making so spontaneous and voluntary. The objective is to face the moral separation between the employee and his work. Indeed, the division of work due to specialization decrease the task value so that the employee is finally no more than just a tool of production.

\subsection{The Knowledge Management Literature Review}

Hedlund (1994) described the KM as a process of interaction between different levels of knowledge: individual, community, organizational and even inter-organizational According to several authors, including Nonaka (1994), the specificity of KM as a process of creation and use of knowledge used in order to increase organizational performance is to attach importance to explicit and tacit knowledge and expertise. The explicit knowledge, as defined by Hall and Andriani (2003), is the one who was captured in a code or a language that facilitates communication, which involves the knowledge and direct experience of knowledge. While the tacit, was defined by, among others, Polanyi (1962) as a non-verbalisable knowledge, intuitive and non-articulable.

\subsection{Conceptual framework of KM and Performance}

Drucker (1993) explains that now, the real resource value creation is knowledge rather than financial capital, nor the tangible with all its infrastructure and means of production. Nonaka and Takeuchi (1997) affirmed that to happen to properly manage this knowledge, it must logically follow a route that passes through a management structure which target their outsourcing, their socialization and their dissemination throughout the organizational performance. 


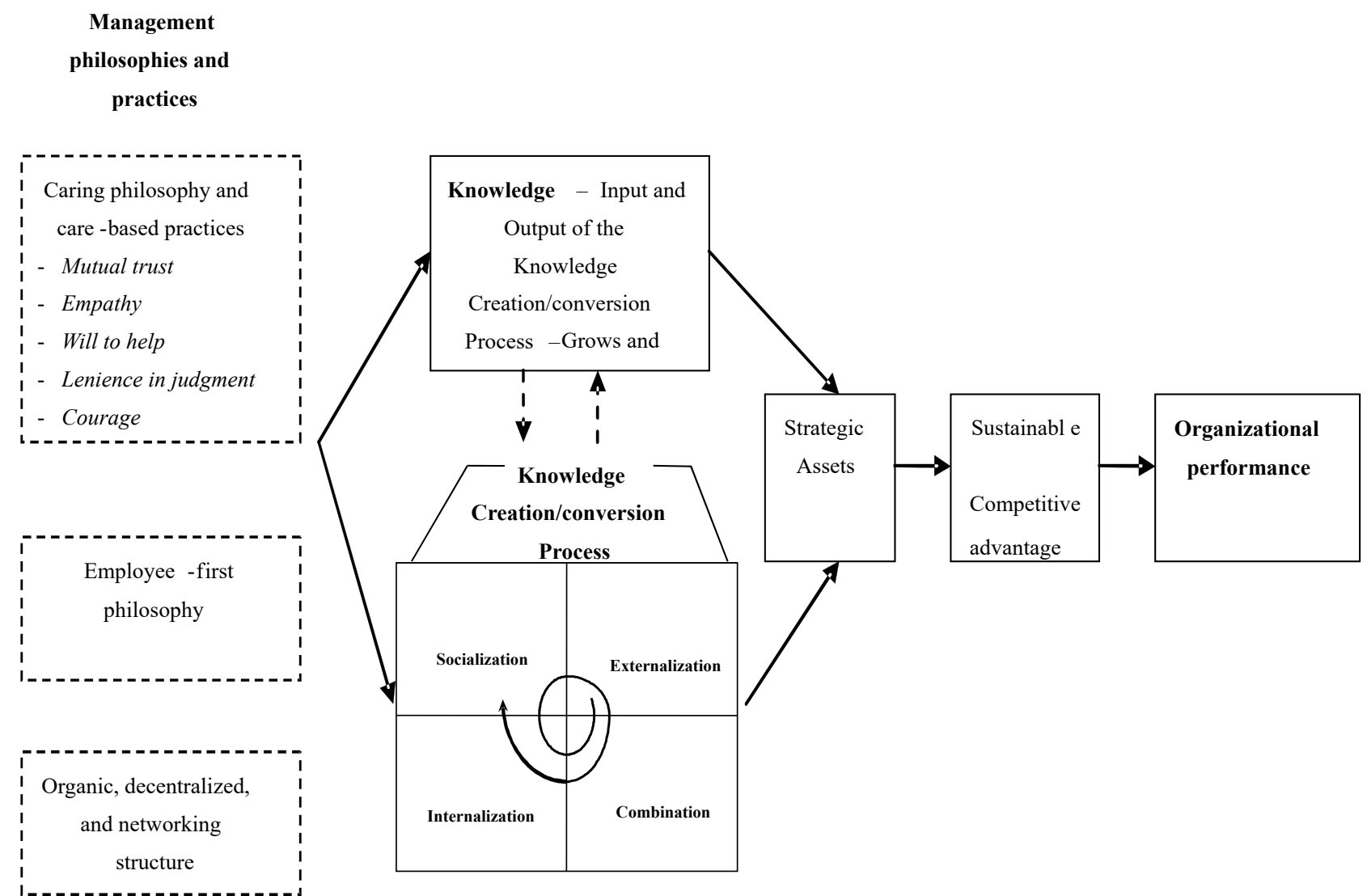

Figure 2. Conceptual relationship between KM and performance (adapted from Kogut \& Zander, 2003)

Figure above (shows) the need to have a new theory of creation in terms of organizational knowledge. The success of such an approach is due to the development of a managerial philosophy which is based on a vision that incorporates the interaction between tacit and explicit dynamically from a lower level to the ontological higher levels (Nonaka \& Takeuchi, 1997). Since the establishment of such a conversion should be based on cooperation between the various stakeholders; mutual trust, empathy and a judgment based on a humanistic vision are involved (Kogut \& Zander (2003)). This form of management described as a humanist and dynamics of justification of personal beliefs are the source of the spiral creative knowledge (Nonaka \& Takeuchi, 1997).

An interactive model that involves socialization, internalization, externalization and combination of all knowledge in all levels of the organisation. Therefore, interaction climbed levels and hierarchies and crystallises at higher ontological levels. This process called conversion (Nonaka \& Takeuchi, 1997) is therefore necessary to share and to connect the explicit and tacit order. The reason is to have real opportunities to make a learning and creative organization in terms of intangibles.

\section{Methodology}

Our methodology is based on interviews semi-led and documentary research. In sum, built managerial, social and socio-cultural development of various concepts found its way through the mechanisms of this methodological approach including field observation, interviews targeting the real way of management practices and documentary research. Hence, our results will address these links in order to compare theory with practice and contribute to see more clearly in the business of nowadays. This will help detect failures and benefits management systems in place and understand the reason for strategic positioning, credibility and the degree of 
necessity of intangibles as a source of innovation and thus creating value.

\subsection{The Sample}

It is composed of nine people including employees, skilled employees and managers in human resources, communication centers and information technologies department. These professionals have different backgrounds, allowing us to collect different views and analysis. Note, before proceeding further, that 4 people among 9 interviewees are part of middle managers in human resources and communication (Nurun) and poles of development processes (for Ericsson). The others are multi-skilled employees involved in information technology in both storage and dissemination of information at the levels of data processing, and design of classic and new methods of products development. The average length of each interview was 45 minutes, due to the unavailability of managers. Indeed, we haven't the opportunity to expand more the questions and the sub-issues. Given these circumstances, we were limited to the most important issues. Note also that the main reason for the choice of these people lies in the degree of importance they attribute to management in relation with the tangible and intangible Knowledge as part of their regular duties. The aim was to target the key people to ensure relevant information in the field.

\subsection{The Data Analysis Software Used}

We used in this empirical study the software "Semato" which is "a semantic analysis software text documents French or English. It is designated for the analysis of focus groups, open questions in surveys, interviews, semi-structured or free of social or literary corpus, newspaper articles, etc. "This software qualitative research will analyze the link and coordination between the main themes,, the most important links, rate of frequency of themes in the interviews to assess subsequently the impact of knowledge management on organizational performance.

\section{Findings of Qualitative Research}

These results give us the possibility to view and compare the answers and determine the importance of knowledge creation in management system and so on the real life of the High Tech enterprises. It will gives us too the possibility to comapre the theorical way of knowledge creation to the real life of the enterprises and determine the obstacles and the strategy for each one and so evaluate the gap between what we do and what we should do to implement the creation knowledge process (See Table 2).

Table 2. Theme co-occurrences

\begin{tabular}{lll}
\hline Theme cooccurrence & Frequency sentence & Text frequency \\
\hline th-knowledge & 165 & 153 \\
th-formation & 40 & 36 \\
th-management & 257 & 231 \\
th-performance & 143 & 133 \\
\hline
\end{tabular}

The following tables analyze the concurrence, to assess the relationship established by the interviewees between management and management of knowledge, on one hand, and organizational performance in all its dimensions, on the other. We remark for example that the concept management was used 165 times in all sentences during all the interviews. The concept of management was used 257 times in all the interviews which means that the managers gives more importance to this term than the others in their speech (See Table 3).

Table 3. Themes frequency on the interviews

\begin{tabular}{lllll}
\hline Theme 1 & Theme 2 & Frequency Thème 1 & Frequency Thème 2 & Cooccurrences Realised \\
\hline th-knowledge & th-performance & 153 & 133 & 77 \\
th-management & th-knowledge & 231 & 153 & 109 \\
th-management & th-performance & 231 & 133 & 90 \\
th-knowledge & th-training & 153 & 36 & 23 \\
th-management & th-training & 231 & 36 & 23 \\
th-performance & th-training & 133 & 36 & 15 \\
\hline
\end{tabular}


As against, we were 77 sentences that contain both the two themes. This Cooccurrence is clearly above the expected cooccurrence, as indicated below (46 times). Therefore, the gap is 31 found in favor of what is realised, giving a probability of obtaining this number of cooccurrences or more $6.3944 \mathrm{E}-06$, executed according to the formula Sémato calculated by Excel (See Table 4).

Table 4. Expected co-occurrences

\begin{tabular}{lll}
\hline Expected co-occurrences & Difference & Probability \\
\hline 46 & 31 & $6,3944 \mathrm{E}-06$ \\
80 & 29 & 0,00039976 \\
70 & 20 & 0,0063154 \\
13 & 10 & 0,0043911 \\
19 & 4 & 0,1955816 \\
11 & 4 & 0,13474105 \\
\hline
\end{tabular}

\subsection{Style Of Management (Qualitative Results)}

Two major types of management approaches discussed in Nurun Inc and Ericsson Canada are: the humanist approach and the financial one. The approaches are described as dynamic and not static, due to necessity of gradual modification of visions and ways of doing depending on the circumstances, the strategic positioning and placement of competitors in the market. Thereby enabling be up to date and adapt to a new technological and competitive environment. In summary, profitability remains quantifiable as basic criterion for evaluating the success

For Ericsson Inc, The process of innovation, research and development has shifted to balance the financial aspect and the human aspect of management style. The speech focuses on the financial recovery, reducing the high protection of staff, to adapt to the new context of crisis and loss of market share by Nokia Inc. The core business is therefore the main concern, since it ensures competitive advantage and resistance against the rapidly changing environment that require innovation and efficiency. This explains the emergence of the technological approach through the large concentration of NITC (the new information technologies and communication), to replace the massive loss of personnel and to be more competitive, with the smallest possible costs, mainly on labour. The Web2.0, Intranet, Internet and the "change point" are the main elements of the NITC who entered massively whole model of management, production, documentation and communication inter-and intra-group, descending and ascending in order to accelerate and facilitate the processes, procedures and the link between the various databases, allowing the exchange of information and knowledge.

Speakers also addressed the issue of appropriate management models, including the interactive model in which research centres such as Ericsson Montreal are involved in making decisions on future research projects, budgets appropriate methods of analysis and production and timelines. This also applies to Nurun, which have the budgetary and managerial autonomy in the operational level, despite its submission to the general guidelines of Quebecor about the obligation of the steady increase in the efficiency and effectiveness. In summary, the strategy which guarantees major guidelines and the desired results (which follows a humanistic approach or financial) pushes these two companies to seek continuous innovation, which is the heart of the concept of knowledge management. The reason is that innovation should exist clearly in the managerial style, which takes into account the intangible as a source of continuous development.

\subsection{Concept of Organisational Performance}

We could then see that all actors within Nurun and Ericsson have not established a direct link, clear and quantifiable between knowledge management and efficiency or performance. The link is as follows: "With a good KM, one is able to produce faster, more quality, it wastes less time to discover and more time to evolve, there is no direct link, but climb best products. The absence of statistics, quantifiable and concrete studies made sure that information is almost non-existent to check the link between the two variables. However, awareness of the importance of the managerial process, which takes account of information, expertise and knowledge to enable innovation and speed of the process, is remarkable throughout interviews.

\subsection{Discussion of Qualitative Results}

Despite all the advantages of the knowledge creation process, the formalization of knowledge can paralyze 
innovation (Brouste \& Cotte, 1999). Creation must abandon preconceived patterns, and therefore should contrary be surprised by events that arouse curiosity, interrogation, and the desire for knowledge. Let us take the example of an artistic director of publicity. It must offer models for the next advertising campaign of a customer. His ideas are born of his research, readings, visits but in no case procedures, formalisms set in advance telling him what to do and how. This example, although obvious in the artistic field, can be applied to all trades.

Finally, we can ask ourselves about the importance degree of experience. By definition, it is personal, specific to an individual and acquired after a long practice. In some cases, it is useless to know what Consequences of his actions, only the personal reiteration of experience can play a real role of teaching. As stated by (Prax, 2003) speech is not enough to convince, individuals need to acquire their own experience, to do errors, which will also be sources of instruction. Thus, formalizing everything cannot guarantee the exact follow-up of the writings. It should also be noted that this adoption of a shared managerial culture underpinned by a participatory management style involving all stakeholders in this new strategic process of creating and disseminating knowledge will be prerequisites for the success of such a large-scale process.

\section{Findings of Quantitative Research}

In this section the results of data analysis are presented and deliberated. In processing the data obtained, the SPSS Version 20 was the software employed. In this section the results of the study are assembled in line with the objectives presented. The points for discussion in this study are accordingly arranged. In particular, the paper starts with the description on the data screening and after that, goodness of measures will be analysed in order to have both the validity as well as the reliability of the variables ascertained. In the last part of this paper, the results of the test related to the relationships are presented.

\subsection{Profile of the Respondents}

The data collection process was taken from selected higher education institute in Malaysia. The background of respondents include category of universities, total years of experience in universities industry, experiences of respondents attached in selected universities in this research and department of universities. The data was collected to give further understanding about the topic and may aid in explaining results of the analysis. Table 5 summarized the description of the demographic characteristics of the participants in this study. The explanation as follows:

Table 5. The demographic data of students $(\mathrm{N}=390)$

\begin{tabular}{llll}
\hline Variables & Coding & Frequency & \% \\
\hline \multirow{2}{*}{ Gender } & Male & 216 & 55.4 \\
& Female & 174 & 44.6 \\
Age & $<30$ years & 159 & 40.7 \\
& $30-40$ years & 129 & 33.1 \\
& $41-50$ years & 102 & 26.2 \\
Current Position & $>50$ years & 202 & 51.8 \\
& CEO & 58 & 14.9 \\
& Supervisor & 31 & 7.9 \\
& Executive & 99 & 25.4 \\
Experience & Manager & 151 & 38.7 \\
& 1-3 years & 104 & 26.7 \\
& 4-7 years & 34 & 8.7 \\
& 8-11 years & 101 & 25.9 \\
\hline
\end{tabular}

Table 5 shows that in the final sample, the collected demographic information confirmed the dominance of females in Jordanian universities higher than male students. More specifically, the descriptive results exhibited that $55.4 \%$ of the respondents were females compared to only $44.6 \%$ males. It is also realized that the majority of the respondents aged between 30-40 years (33.1\%), less than 30 years old (40.7\%), and between 41-50 years old (26.2\%).

With regard to respondents of qualification, the majority of respondents (51.8\%) were CEO, and the lowest were from Executive (7.9\%) respectively. Table 4.3 also displays that experience of respondents aged between 1-3 years $(38.7 \%)$, respondents aged between $4-7$ years $(26.7 \%)$, respondents aged from 12 to above years $(25.9 \%)$, 
and while least representing $8.7 \%$ are from aged between $8-11$ years .

\subsection{Instrument Reliability}

The researcher tested the questionnaire for its reliability and for internal consistency of its items using the Reliability Analysis, with the value of Cronbach's alpha coefficient serving as the indicator of reliability. The value of Cronbach's alpha coefficient should be equal to, or higher than, 0.70 for the instrument to be considered as sufficiently reliable. Table1.6 shows that the values of Cronbach's alpha coefficient were larger than 0.70 for all seven constructs of the research instrument. They ranged from 0.721 for the IP construct to 0.779 for the KD construct, hence indicating that the seven constructs of the research questionnaire were all reliable and that their items have high internal consistency.

Table 6. Results of reliability analysis of the research instrument

\begin{tabular}{lccc}
\hline \multicolumn{4}{l}{ ConstructNo of ItemsItem deletedCronbach's Alpha Coefficient } \\
\hline KD & 4 & None & .779 \\
KS & 3 & None & .775 \\
KOL & 4 & None & .771 \\
ELC & 4 & None & .726 \\
ILC & 3 & None & .771 \\
IP & 3 & None & .721 \\
\hline
\end{tabular}

On the other hand, the third column in Table 6 indicates that there was no need for removal of any instrument item. In this respect, Nunnally (1978) suggested that if removal of an instrument item leads to only small increment in value of Cronbach's alpha coefficient, then there will be no need for removal of this item. In the current study, no single item was eliminated from the questionnaire because elimination of no item resulted in tangible increase in instrument reliability.

\subsection{Descriptive Analysis}

A descriptive analysis of the research data was conducted in an attempt to assess the perceptions of the sample members of the levels of importance of the five independent variables in determining their intentions to use m-banking services in Oman and their actual use of these services. In this context, the means, standard deviations, minima, and maxima of the respondents' feedback on the research variables are reported in Table 7. For ease of interpretation of the five levels of agrrement on the instrument items and variables, this study classified these five levels into three categories as follows: low level, which is characterized by mean scores less than 2.33; high level, which corresponds to mean scores greater than 3.67; and moderate level, which represents mean agreement scores falling within the range of 2.33 to 3.67 .

Table 7. Descriptive Statistics for, and coefficients of correlations between, the study variables $(\mathrm{N}=216)$

\begin{tabular}{lccccccc}
\hline Construct & $\mathbf{M}^{\mathrm{a}}$ & $\mathbf{S D}^{\mathrm{b}}$ & $\mathbf{1}$ & $\mathbf{2}^{\mathrm{c}}$ & $\mathbf{3}$ & $\mathbf{4}$ & $\mathbf{5}$ \\
\hline KD & 3.74 & 3.643 & 0.76 & $0.55^{* *}$ & $0.41^{* *}$ & $0.53^{* *}$ & $0.32^{* *}$ \\
KS & 3.82 & 3.849 & & $0.48^{* *}$ & $0.42^{* *}$ & $0.51^{* *}$ & $0.37^{* *}$ \\
KOL & 3.74 & 3.767 & & & $0.37^{* *}$ & $0.62^{* *}$ & $0.56^{* *}$ \\
ELC & 3.88 & 3.829 & & & & $0.54^{* *}$ & $0.62^{* *}$ \\
ILC & 3.86 & 3.793 & & & & & $0.74^{* *}$ \\
IP & 3.69 & 3.834 & & & & & \\
\hline
\end{tabular}

a. M: Mean.

b. SD: Standard Deviation.

c. **: The association is significant at the 0.01 level of significance.

\subsection{Hypothesized Model Analysis}

Following Tippins and Sohi (2003), we used the elliptically reweighted least square method as the estimation procedure for testing our hypothesized model. We tested for the presence of a mediating effect by performing a competing model analysis. The first model (direct effect) examined the direct relationship between KM practice and firm innovation performance. This model was used to test Hypothesis 1, which posits a positive and significant relationship between KM practice and firm innovation performance. The second model (direct effect) 
examined the direct relationship between Knowledge oriented Leadership and firm innovation performance. This model was used to test Hypothesis 2, which posits a positive and significant relationship between KM practice and firm innovation performance. The third model (direct effect) examined the direct relationship between KM Dynamics Capabilities and firm innovation performance. This model was used to test Hypothesis 3, which posits a positive and significant relationship between KM practice and firm innovation performance.

The four model (direct effect) examined the direct relationship between KM practice and KM dynamic capabilities. This model was used to test Hypothesis 4, which posits a positive and significant relationship between KM practice and firm innovation performance. The fifth model (direct effect) examined the direct relationship between Knowledge oriented Leadership and KM dynamic capabilities. This model was used to test Hypothesis 5, which posits a positive and significant relationship between KM practice and firm innovation performance. Figure 3 is direct model analyse.

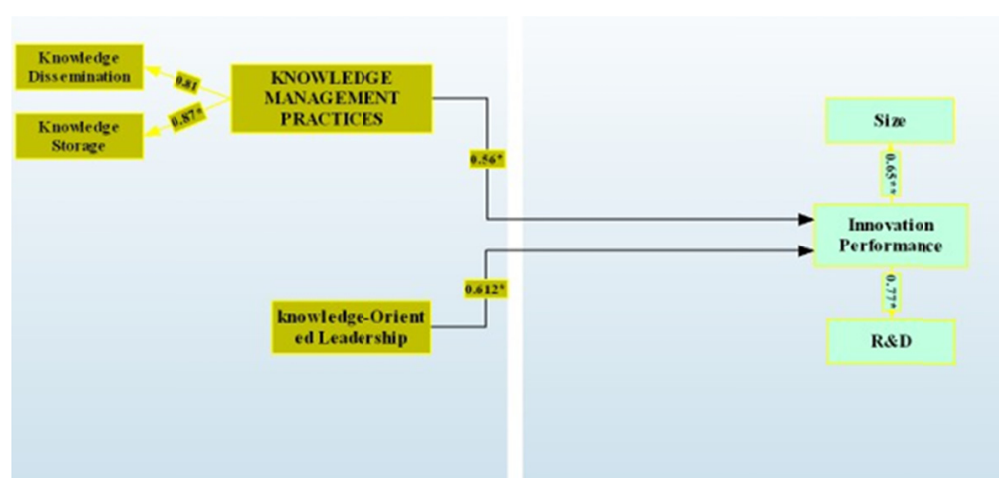

Figure 3. Direct model

\subsection{Mediating Effect of the Hypothesized Model}

A mediation model (partial mediation) examined the same relationship with KM dynamic capabilities acting as a mediator between Knowledge oriented Leadership and innovation performance, it is also KM dynamic capabilities acting as a mediator and between KM practice and firm innovation performance. Figure 1.4 Indirect Model of Mediation and table 9. Total effects of mediator in the research model.

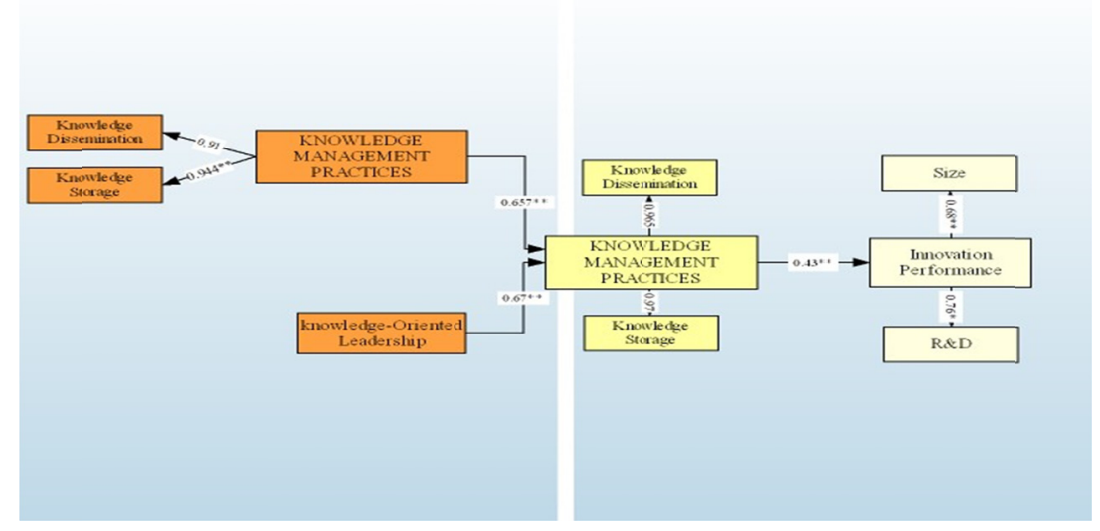

Figure 4. Indirect model of mediation

Table 8. Total effects of mediator in the research model

\begin{tabular}{llll}
\hline & \multicolumn{2}{c}{ Endogenous Variable (Organizational Behavior) } \\
& Indirect effect & Direct effect & Total effect \\
\hline Leaders & 0.381 & $0.325^{* *}$ & $0.436^{* *}$ \\
\hline
\end{tabular}




\section{Conclusions}

In summary, this study could successfully determine impacts of several factors on the IP of the user to influence the of knowledge management on managerial performance in the high tech sector. Furthermore, the study highlighted influence of knowledge management on the high tech sector and defined its relation with the user's IP to influence the of knowledge management on managerial performance. the findings of this study are anticipated to contribute to an in-depth understanding of how the studied factors, in general, KMP, KOL, KM dynamic capabilities, and innovation performance, in particular, influence the of knowledge management on managerial performance services in developing countries. In other respects, the outcomes of this study have potential play substantial role in boosting the level of adoption of the provided in the high tech sector services in these countries. therefore, future research must investigate the likely effects of factors on in the high tech sector as well as their potential mediating effects on the relationships between (i) the investigated factors and the user's IP to influence the of knowledge management on managerial performance, and (ii) the studied factors and the user's $\mathrm{km}$ dynamic capabilities of the high tech sector services.

The managerial philosophy that will meet both tacit and explicit knowledge is transforming the organization into learning and innovative one. Thus, to create new expertise and talent capable of creating competitive advantage and meet the requirements of performance, both quantitatively and qualitatively aspect of knowledge management spiral of knowledge (Nonaka, \& Takeuchi, 1999). We were able to conclude that knowledge management in these organizations has resulted mainly in terms of information, while the main aspect of the expertise, talent tacit, intuition, perception, emotions, remains in absolute and in most cases, unnoticed, devalued or unknown. Thus, the process of knowledge creation focuses mainly on the level of the quantifiable and measurable knowledge (via the information technology), and does not dig in everything that is unquantifiable, tacit and subjective that are still largely neglected. Indeed, make an inventory of existing knowledge, note the differences between the current state of knowledge and desirable state, and then anticipate what would be lost if an individual or group responsible had to leave the company, can prove a good way to justify the introduction of knowledge management.

\section{References}

Aktouf, O. (1994). Le Management entre tradition et renouvellement.

Alavi, M., Kayworth, T. R., \& Leidner, D. E. (2005). An empirical examination of the influence of organizational culture on knowledge management practices. Journal of Management Information Systems, 22(3), 191-224.

Brouste, P., \& Cotte, D. (1999). Les tablettes....d'Ourouk. Le Knowledge Management. Paris: Ourouk.

Castells, M. (1996). The Information Age: Economy, Society and Culture. The rise of the network society.

Edvinsson, L., \& Malone, M. S. (1997). Intellectual capital: realizing your company's true value by finding its hidden brainpower.

Hall, R., \& Andriani, P. (2003). Managing knowledge associated with innovation. Journal of business Research, 56(2), 145-152.

Hedlund, G. (1994). A model of knowledge management and the N-form corporation. Strategic Management journal, 15(S2), 73-90.

Ingham, M., Takeuchi, H., Nonaka, I., \& Koenig, G. (1997). La connaissance créatrice: la dynamique de l'entreprise apprenante. De Boeck Université.

Kogut, B., \& Zander, U. (1992). Knowledge of the firm, combinative capabilities, and the replication of technology. Organization science, 3(3), 383-397.

Kogut, B., \& Zander, U. (1993). Knowledge of the firm and the evolutionary theory of the multinational corporation. Journal of International Business Studies, 24(4), 625-645.

Leonard, D., \& Sensiper, S. (1998). The role of tacit knowledge in group innovation. California Management Review, 40(3), 112-132.

Lin, Y., \& Dalkir, K. (2010). Factors affecting KM implementation in the Chinese community. International Journal of Knowledge Management (IJKM), 6(1), 1-22.

Mason, D., \& Pauleen, D. J. (2003). Perceptions of knowledge management: a qualitative analysis. Journal of Knowledge Management, 7(4), 38-48.

Melville, N., Kraemer, K., \& Gurbaxani, V. (2004). Information technology and organizational performance: An integrative model of IT business value. MIS Quarterly, 28(2), 283-322. 
Nonaka, I. (1991). The knowledge-creating company Harvard business review November-December.

Polanyi, M. (1967). The tacit dimension. Coll.«Terry lectures 1962».Garden City, N.Y.Doubleday, 198 p.

Rix-Lièvre, G., \& Lièvre, P. (2012). La dimension «tacite» des connaissances expérientielles individuelles: une mise en perspective théorique et méthodologique. Management international/International Management/Gestiòn Internacional, 16, 21-28.

Shin, M. (2004). A framework for evaluating economics of knowledge management systems. Information \& Management, 42(1), 179-196.

Teece, D. J. (2004). Knowledge and competence as strategic assets. Handbook on Knowledge Management, 1, $129-152$.

Wasko, M. M., \& Faraj, S. (2005). Why should I share? Examining knowledge contribution in networks of practice. MIS Quarterly, 29(1), 35-57.

Wenger, E. C., \& Snyder, W. M. (2000). Communities of practice: The organizational frontier. Harvard Business Review, 78(1), 139-146.

Woodman, M., \& Zade, A. (2012). Five grounded principles for developing knowledge management systems. Electronic Journal of Knowledge Management, 10(2), 183.

Yuan, Y. C., Gay, G., \& Hembrooke, H. (2006). Focused activities and the development of social capital in a distributed learning "community". The Information Society, 22(1), 25-39.

Zara, O. (2008). Le management de l'intelligence collective: vers une nouvelle gouvernance. M21 Editions.

Zheng, W. (2005). The impact of organizational culture, structure, and strategy on knowledge management effectiveness and organizational effectiveness. University of Minnesota. Management Effectiveness and Organizational Effectiveness, UMI Dissertation Services, ProQuest, Minneapolis, MN.

\section{Copyrights}

Copyright for this article is retained by the author(s), with first publication rights granted to the journal.

This is an open-access article distributed under the terms and conditions of the Creative Commons Attribution license (http://creativecommons.org/licenses/by/4.0/). 